for primary health care workers to identify these disorders, even when subjects do not draw attention to them.

Elderly people may not consult their general practitioner about hearing and visual impairments, urinary incontinence, or decline in cognitive function. This may be owing to the insidious onset of these conditions, acceptance of these types of symptoms as "normal" manifestations of the aging process, or embarrassment. Alternatively, elderly subjects might consider expensive medical treatment wasteful for the short period they have still to live, as the present cohort is the first to benefit from the welfare state.

We had considered identifying unknown cases of, for instance, chronic leukaemia, hypothyroidism, or myeloma. Except for the occasional deviation in laboratory results and two cases of hypothyroidism, no serious, previously unknown disease was found in the total study population. Most diagnoses were already well documented and known to the general practitioner.
We conclude that taking a medical history in subjects aged 85 or more provides an accurate and complete picture of the prevailing disorders at the time of the interview and of lifetime diagnoses.

We thank the general practitioners for their cooperation This study was supported by a grant of the National Institutes of Health of the USA No RO1 AG06354.

1 Kelsey JL, O'Brien LA, Grisso JA, Hoffman S. Issues in carrying out epidemiologic research in the elderly. Am J Epidemiol 1989;130:857-66. Davis PB, Robins LN. History-taking in the elderly with and withou cognitive impairment. $\mathcal{F}$ Am Geriatr Soc 1989;37:249-55.

3 Rodgers WL, Herzog AR. Interviewing older adults: the accuracy of factua information. F Gerontol 1987;42:387-94.

4 Folstein MF, Folstein SE, McHugh PR. "Mini-mental state:" a practica method for grading the cognitive state of patients for the clinician. I Psychiatr Res 1975;12:189-98.

5 O'Connor DW, Pollitt PA, Hyde JB, Brook CPB, Reiss BB, Roth M. Do general practitioners miss dementia in elderly patients? BMF 1988;297: $1107-10$.

(Accepted 30 October 1991)

\section{Does a truss benefit a patient with inguinal hernia?}

N W Law, J E Trapnell

\section{Royal Bournemouth Hospital, Bournemouth, Dorset BH7 7DW $\mathrm{N}$ W Law, senior registrar in general surgery \\ J E Trapnell, consultant general surgeon}

Correspondence to: Mr Trapnell.

BMF 1992;304: 1092

Trusses are prescribed for elderly patients with an inguinal hernia because general practitioners consider the risks of surgery to be excessive, but there have been few investigations into the benefits and acceptability of the truss for the control of groin hernias. We report on 250 consecutive patients referred for surgical repair of a hernia, 52 of whom were fitted with a truss before attending outpatient departments.

\section{Patients, methods, and results}

A total of 52 new patients ( 50 men, two women) referred to two surgical outpatient departments for inguinal hernia repair over a six month period and who had been prescribed a truss before their attendance were assessed. We asked the patients when the truss was fitted, whether instructions were given on how to apply the truss, whether the truss was comfortable, whether they actually wore it, and whether they thought it controlled the hernia partially or completely. Finally, we asked the patients to put the trusses on and then examined them to see whether the truss controlled the hernia when the patient was standing.

The median age of the patients was 70 (range 35-90) years, and they had worn a truss for a median of 35 (2-240) months. Eleven (21\%) patients had been prescribed a truss before referral to a surgeon. Al trusses had been fitted by a surgical supplier but only $23(44 \%)$ patients said they had received instructions on how to put on the truss, and $35(77 \%)$ fitted the truss while standing up. The truss was worn most of the time by $49(94 \%)$ patients, but $33(64 \%)$ found the truss uncomfortable. Partial or complete control of the hernia was achieved in $16(31 \%)$ patients: the truss did not control the hernia in $36(69 \%)$.

\section{Comment}

Surgical repair is the best treatment for groin hernias and only in exceptional circumstances, when a patient is unfit for surgery or refuses an operation, should a truss be considered.

A fifth of our patients were prescribed a truss before seeing a surgeon, even though the delay between referral and a clinic appointment was only $8-12$ weeks. Similarly, Ljungdahl found $17 \cdot 8 \%$ of patients were fitted with a truss before consultation for hernia repair. ${ }^{1}$

The benefits of a truss are often overstated. Our results show that most patients found the truss uncomfortable to wear, but others have claimed that if it is fitted correctly a truss may relieve symptoms in up to $65 \%$ of patients. ${ }^{1}$ A truss is rarely successful in maintaining a continuous control of a hernia, however, and most patients wear it only intermittently. ${ }^{1}$ It was also a feature of our cases that the longer the patient had had the truss, the more unsatisfactory it had become. The poor hernia control in our patients was exacerbated by incorrect fitment as most applied the truss while standing. This reflects either inadequate instruction given by the fitters or poor comprehension by patients.

A truss increases the probability of complications, which include strangulation of the hernia, atrophy of the spermatic cord, and atrophy of the fascial margins. This allows the defect to enlarge and makes subsequent repair more difficult. ${ }^{2}$

About 40000 trusses are sold annually in the United Kingdom, mostly supplied through retail outlets rather than hospitals. ${ }^{3}$ Many patients are therefore provided with a truss either before or without the benefit of a surgical opinion. The mortality from elective hernia repair is now almost zero, and with improved local and regional anaesthesia virtually no patient need be refused operation on medical grounds.

We suggest that a surgical opinion should be obtained before a truss is prescribed. This should reduce the need for an antiquated surgical appliance which is uncomfortable and often fails to fulfil its purpose. This policy would also save money.

\footnotetext{
1 Ljungdahl I. Inguinal and femoral hernia. Acta Chir Scand 1973;439(suppl)

Condon RF, Nyhus LM Complications of groin hernia repair. Surg Clin N Am $1971: 51: 1325-36$.
}

3 Goldman M. Trusses. BMF 1991;302:238-9.

(Accepted 21 fanuary 1992)

\section{Correction}

Effect of a heat and moisture retaining mask on exercise induced asthma

A typesetting error occurred in this short report by E J Stewart and others (22 February, pp 479-80). In the table the figures in the last two columns should be transposed. 